\title{
ENSAIOS
}

\section{O PAPEL DO CONTADOR NA PRESTAÇÃO DE CONTAS ELEITORAIS}

\section{RESUMO}

Este ensaio tem por objetivo analisar o papel do contador na "Prestação de Contas dos Partidos Políticos e dos Candidatos", evidenciando as atividades dos contadores, tendo em vista que este profissional desenvolve o trabalho, desde as classificações contábeis às digitações das movimentações financeiras das arrecadações e os gastos de campanha, bem como, ao final da elaboração do trabalho desenvolvido, apresenta como resultado as peças contábeis. Contudo, para que se possa apresentar esse resultado ao Juiz, é necessária a assinatura de um advogado, mesmo que tenha participado ou não no desenvolvimento do serviço contábil. Em outros juízos, tais como na justiça trabalhista, varas cíveis, o contador, ao atuar como perito, apresenta os Laudos Periciais diretamente em cartório, sendo, portanto, desnecessária a figura do advogado para assinar as peças contábeis. Diante disso, os principais resultados do estudo permitem concluir que a perícia é de exclusividade do contador e, nesse aspecto, ele deve apresentar seu trabalho, assim como responder às diligências que lhe forem demandadas, sem que um advogado assine o que por ele não foi realizado, haja vista que o patrono não participou da elaboração contábil; tal situação fere o Código de Ética dos Advogados.

Palavras-chave: Contador. Advogado. Prestação de Contas Eleitoral.

\section{INTRODUÇÃO}

A crescente necessidade assumida pela Justiça Eleitoral no que tange às prestações de contas dos Candidatos nas eleições e dos partidos políticos, anualmente, exige a atuação do profissional da contabilidade, o qual realiza o trabalho, desde as classificações contábeis às digitações das movimentações financeiras das arrecadações e dos gastos eleitorais, cujo resultado final corresponde às

Mario Souza da Rocha e.mariorocha@gmail.com Graduado em Ciências Contábeis e Gestão Financeira. Ex-Superintendente Regional do Trabalho e Emprego de Roraima. peças contábeis a serem aprovadas ou não. O fato é que esse profissional não pode requerer a apresentação das prestações de contas elaboradas por ele perante a Justiça Eleitoral, se não constar no bojo do trabalho desenvolvido, a assinatura de um advogado, mesmo que este não tenha participado do feito.

Na Justiça Trabalhista e Varas Cíveis, o Contador leva o re- 
sultado de seu trabalho, nos casos em que atua como perito diretamente ao Juiz, consoante estatui o Código Civil e o Código de Processo Civil, sem que haja a necessidade da assinatura de um advogado para atestar o trabalho elaborado por ele. Busca-se, neste estudo, discutir, com base nesse pressuposto, a desnecessária presença de um advogado para assinar as peças contábeis apresentadas à Justiça Eleitoral, haja vista que o advogado está assinando um trabalho realizado por outro profissional, ferindo, claramente, o que dispõe o Código de Ética dos Advogados e dos Contadores.

A partir desse entendimento, observa-se que a apresentação das prestações de contas eleitorais deve embasar-se, por analogia, ao que dispõe o artigo 477 do Código de Processo Civil, o qual preconiza que os laudos periciais são realizados pelos Peritos Contadores, não trazendo, portanto, a exigência da assinatura de um patrono. Com isso, elimina a obrigatoriedade do contador em apresentar o resultado de seu trabalho em juízo eleitoral prescindido da assinatura de um Advogado.

Diante do exposto, este ensaio tem como objetivo analisar o papel do contador na "Prestação de Contas dos Partidos Políticos e dos Candidatos," tendo como pressuposto que a prestação de contas dos partidos políticos e dos candidatos é atividade exclusiva dos contadores, de modo que a assinatura de um advogado no serviço contábil torna-se dispensável, na medida em que o desenvolvimento do trabalho é fruto tão somente do trabalho de um contador, que é o profissional detentor do conhecimento técnico para elaborá-la.

Para atender ao objetivo da pesquisa, é elaborado um levantamento comparativo de como funciona o encaminhamento dos laudos periciais realizados pelo contador que atua como perito judicial nas Justiças Comum e do Trabalho, assim como o que estabelece a lei sobre o caso em comento. Para tanto, tem-se uma pesquisa exploratória para conhecer o problema ora estudado e atingir o objetivo proposto, que é esclarecer e modificar conceitos e ideias, seguindo, assim, as recomendações de Gil (2008). Destaca-se que grande parte do estudo foi embasada na legislação pertinente e na bibliografia que trata do tema, fazendo um comparativo destes dois pilares.

\section{A PROFISSÃO CONTÁBIL}

O Contador tem a responsabilidade de gerar informações de todas as operações realizadas por uma empresa, assim como demonstrar os resultados para o processo de tomada de decisão pelos administradores da empresa e demais usuários; tem ele que estar no centro do processo de transformações para atender ao mundo globalizado.

De acordo com Nasi (1994 apud KRAEMER, 2000, p. 55), para que isso aconteça:

O Contador deve estar no centro e na liderança deste processo, pois, do contrário, seu lugar vai ser ocupado por outro profissional. O Contador deve saber comunicar-se com as outras áreas da empresa. Para tanto, não pode ficar com os conhecimentos restritos aos temas contábeis e fiscais. O Contador deve ter formação cultural acima da média, inteirando-se do que acontece ao seu redor, na sua comunidade, no seu Estado, no seu País e no mundo. O Contador deve ter um comportamento ético-profissional inquestionável. O Contador deve participar de eventos destinados à sua permanente atualização profissional (educação continuada). O Contador deve estar consciente de sua responsabilidade social e profissional.

Por fim, cabe salientar que o profissional da contabilidade tem entre outras funções o papel de resolver enigma do processo administrativo e financeiro, não como obrigado por deliberação, mas como responsáveis pelo arrolamento dos dados que preocupam aos usuários. E ter confiança de que o executivo se norteie por elementos que favoreça a tomar a melhor decisão, por meio de seus 
documentos contábeis, bem como os caminhos que devem ser percorridos (SILVA, 2003, p. 3).

Nesta senda, o contador tem aptidão para analisar contas, bem como traçar estratégias a serem tomadas; no entanto, seu trabalho não se limita a isto, uma vez que deve estar inteirado aos acontecimentos globais.

\subsection{OBRIGATORIEDADES DE TER UM CONTADOR NA PRESTAÇÃO ELEITORAL DE CONTAS}

Desde que foi estabelecida pela lei dos partidos políticos que estes e os candidatos deveriam apresentar as prestações de contas para a Justiça Eleitoral e tendo nas normas de contabilidade que esse trabalho deve ser realizado por um profissional de contabilidade, a exigência de que essa prestação fosse feita e assinada obrigatoriamente por um contador só ocorreu a partir das eleições de 2014.

Define Mattos (2014, p. 39):

A escrituração contábil, por sua vez, só pode ser efetuada por CONTADOR ou TÉCNICO EM CONTABILIDADE, com inscrição regular no Conselho Regional de Contabilidade da sua respectiva jurisdição, ex vi do disposto nos arts. 12 e 25 do Decreto-Lei $n^{\circ}$ 9.295/46. Avanço importante na Resolução TSE n 23.406 é a exigência de que as prestações de contas sejam firmadas por profissional da contabilidade. Tal ato é prerrogativa profissional, sendo, portanto, condição necessária para a legitimação dos procedimentos contábeis. O reconhecimento expresso do Tribunal Superior Eleitoral acerca da participação imperativa do profissional da contabilidade na elaboração das prestações de contas evidencia, em consequência, a relevância da escrituração contábil como suporte indispensável de todo o processo. É exatamente em nome da transparência do processo eleitoral que os partidos políticos devem manter, em sua escrituração, contas contábeis específicas dos recursos destinados às campanhas eleitorais, a fim de permitir a sua segregação de quaisquer outros e a identificação de sua origem.

Como acentuado, o serviço de prestação de contas a ser realizado por um contador tornou-se imprescindível e obrigatório perante a Justiça Eleitoral, com vistas a deixar cristalina e bem delineada a destinação dos recursos financeiros nas campanhas eleitorais.

\section{A PRESTAÇÃO DE CONTAS NA JUSTIÇA ELEITORAL}

A prestação de Contas na Justiça Eleitoral é o ato pelo qual o candidato, o Comitê Financeiro e/ou os partidos políticos informam à Justiça Eleitoral sobre a origem da arrecadação de recursos e as despesas da campanha.

Os candidatos, os comitês financeiros e os partidos políticos devem prestar contas ao final do processo eleitoral, ao passo que os partidos políticos devem apresentar, anualmente, toda a documentação contábil. Na prestação de contas final, devem ser identificados os nomes dos doadores de cada centavo arrecadado, bem como os respectivos valores doados.

Neste sentido, colaciona-se a conceituação sobre o tema, conforme a Lei 9.096/95 (BRASIL, 1995) e suas alterações: “art. 30. O partido político, através de seus órgãos nacionais, regionais e municipais, deve manter escrituração contábil, de forma a permitir o conhecimento da origem de suas receitas e a destinação de suas despesas." (BRASIL, 1995).

Observa-se que essas atividades são exclusivas dos profissionais de contabilidade. Giavarina (2002, p. 193) define:

As prestações de contas dos candidatos às eleições Majoritárias serão feitas por intermédio do comitê Financeiro, devendo ser acompanhadas dos extratos das contas bancárias referentes à movimentação dos recursos financei- 
ros usados na campanha e da relação dos cheques recebidos, com a indicação dos respectivos números, valores e emitentes. As prestações de contas dos candidatos às eleições proporcionais serão feitas pelo comitê financeiro ou pelo próprio candidato.

Corroborando o assunto, Giavarina (2004, p. 295) argumenta: “o partido político através de seus órgãos nacionais, regionais e municipais, deve manter escrituração contábil, de forma a permitir o conhecimento da origem de suas receitas e a destinação de suas despesas."

Percebe-se, portanto, que, para o desenvolvimento da escrituração contábil, há a necessidade da presença de um contador, que é o profissional detentor do conhecimento técnico-científico para elaborar as prestações de contas.

\subsection{DAS PEÇAS QUE COMPÕEM A PRESTAÇÃO DE CONTAS NA JUS- TIÇA ELEITORAL}

Para cada eleição, uma lei, assim o Tribunal Superior Eleitoral estabelece as regras por meio de Resoluções para cada pleito.

A Lei $n^{\circ}$ 9.504/97 (BRASIL, 1997), assim dispõe: "art. 17-A. A cada eleição caberá à lei, observadas as peculiaridades locais, fixar até o dia 10 de junho de cada ano eleitoral o limite dos gastos de campanha para os cargos em disputa; não sendo editada lei até a data."

Assim, o Tribunal Eleitoral tem até o dia 5 de março de cada ano eleitoral para aprovar as resoluções, contendo as regras que regerão as eleições; entre elas, a que estabelece a Prestação de Contas.

\subsubsection{Peças para a Prestação de Contas dos Partidos Político}

Os documentos necessários para a prestação de contas dos partidos políticos estão elencados no artigo 14 da Resolução do TSE 21.841/2004, in verbis (BRASIL, 2004):
I. Balanço Patrimonial;

II. Demonstração do Resultado do Exercício;

III. Contas Bancárias;

IV. Concılıação Bancária;

V. Demonstrativo de Pagamento e/ou Assunção de Obrigações de Outras Esferas Partidárias;

VI. Agentes Responsáveis;

VII. Demonstrativo de Recursos Recebidos do Fundo Partidário;

VIII. Demonstrativo de Recursos Distribuídos do Fundo Partidário;

IX. Demonstrativo de Doações Financeiras Recebidas;

X. Demonstrativo de Doações Estimáveis Recebidas;

XI. Demonstrativo de Obrigações a Pagar;

XII. Demonstrativo de Dívidas de Campanha;

XIII. Demonstrativo de Receitas e Gastos;

XIV. Demonstrativo de Transferências de Recursos Efetuadas Para Campanhas Eleitorais A Candidatos, Comitês Financeiros e Diretórios Partidários;

XV. Demonstrativo de Contribuições Recebidas;

XVI. Demonstrativo de Sobras de Campanha Financeira Recebida;

XVII. Demonstrativo de Sobras de Campanha de Bens Permanentes;

XVIII. Demonstrativo dos Fluxos de Caixa.

Constata-se, a partir do artigo 14 da Resolução do TSE 21.841/2004 (BRASIL, 2004), que os procedimentos e os formulários que fazem parte do elenco de documentos para as peças da prestação de contas são das atividades exclusivas dos profissionais de Contabilidade.

\subsubsection{Peças Para a Prestação de Contas do Candidato}

A Resolução do TSE 23.463/2015 (BRASIL, 2015a), em seu artigo 48, elenca os documentos necessários para a prestação de contas, vejamos: 
I. Ficha de Qualificação do Candidato ou do Comitê Financeiro, conforme o caso;

II. Demonstrativo dos Recibos Eleitorais Recebidos;

III. Demonstrativo dos Recibos Eleitorais Distribuídos, no caso de prestação de contas de comitê financeiro;

IV. Demonstrativo dos Recursos Arrecadados;

V. Demonstrativo das Despesas Pagas após a Eleição;

VI. Demonstrativo de Receitas e Despesas;

VII. Demonstrativo do Resultado da Comercialização de Bens e da Realização de Eventos;

VIII. Conciliação Bancária;

IX. Termo de Entrega à Justiça Eleitoral dos recibos eleitorais não utilizados, acompanhado dos respectivos recibos;

X. Relatório de Despesas Efetuadas;

XI. Demonstrativo de Doações Efetuadas a Candidatos ou a Comitês Financeiros;

XII. Extratos da conta bancária aberta em nome do candidato;

XIII. Canhotos dos recibos eleitorais utilizados em campanha;

XIV. Guia de depósito comprovando o recolhimento à respectiva direção partidária das sobras financeiras de campanha, quando houver;

XV. Declaração da direção partidária comprovando o recebimento das sobras de campanha constituídas por bens e/ou materiais permanentes, quando houver;

XVI. Documentos fiscais que comprovem a regularidade dos gastos eleitorais realizados com recursos do Fundo Partidário, quando houver.

Os procedimentos e os formulários que fazem parte do elenco de documentos para as peças da prestação de contas são igualmente das atividades exclusivas dos profissionais de Contabilidade.

\section{A PERÍCIA CONTÁBIL}

A perícia contábil é uma atividade do ramo da contabilidade que é realizada exclusivamente pelo Contador. É, na realidade, uma das atividades de maior relevância exercidas pelo contador, a qual exige profundos conhecimentos e dedicação, não só da contabilidade propriamente dita, mas de outras áreas afins, bem como uma atitude ética e perseverante.

O contador, quando no exercício da função de perito, tem a obrigação de evidenciar todos os esforços possíveis em busca da veracidade dos fatos, transcrever em Laudo Pericial os resultados que obteve dos exames realizados, agindo sempre com o máximo de independência ética e absoluta sensatez.

A perícia contábil é uma atividade que, apesar da relevância e da importância, ainda não é tida como profissão, Apesar dos obstáculos a serem vencidos pela classe contábil para que a perícia contábil tenha um melhor destaque, principalmente, quanto à perícia judicial, ela pode ser executada com maior rigor técnico cientifico. "A perícia judicial consiste no meio pelo qual pessoas habilitadas, capacitadas e de idoneidade moral, assumem o compromisso de bem e fielmente desempenhar os deveres de seu cargo, na forma e sob as penas da lei." (CABRAL, 2003, p. 38).

Com o novo Código de Processo Civil que determina a criação do Cadastro de peritos no âmbito da Justiça, cujo Conselho Nacional de Justiça - CNJ criou uma comissão para que seja elaborada uma resolução nesse sentido, o Conselho Federal de Contabilidade - CFC igualmente estabeleceu norma no mesmo sentido.

No que tange às atividades do contador, relacionadas às atividades de perito, temos como conceito definido no Código de Processo Civil o que segue: "art. 477. O perito protocolará o laudo em juízo, no prazo fixado pelo juiz, pelo menos 20 (vinte) dias antes da audiência de instrução e julgamento." (BRASIL, 2015b).

Consoante ao que dispõe o artigo supramencionado, o Contador no bojo da atuação pericial protocolizará o laudo desenvolvido por 
ele, não havendo necessidade de um advogado para assinar o trabalho contábil realizado per ele.

\subsection{O LAUDO PERICIAL}

Em conformidade com o estabelecido na Resolução 1.041/05 do CFC NBC T 13.6 - Laudo Pericial Contábil de 26 de agosto de 2005 (PORTAL DE CONTABILIDADE, 2005):

13.1.1.1 - O laudo pericial contábil e ou parecer pericial contábil têm por limite os próprios objetivos da perícia deferida ou contratada.

13.1.2 - A perícia contábil, tanto a judicial como a extrajudicial e a arbitral, é de competência exclusiva de contador registrado em Conselho Regional de Contabilidade.

13.1.3 - Nos casos em que a legislação admite a perícia interprofissional, aplica-se o item anterior exclusivamente às questões contábeis, segundo as definições contidas na Resolução CFC n. ${ }^{\circ} 560 / 83$.

13.1.4 - A presente Norma aplica-se ao perito-contador nomeado em Juízo, ao contratado pelas partes para a perícia extrajudicial ou ao escolhido na arbitragem; e, ainda, ao perito-contador assistente indicado ou contratado pelas partes.

Diante disto, o laudo pericial é o resultado do trabalho escrito do Perito-Contador cujo objetivo final é levar informações técnicas especializadas e precisas para que sirva de balizador para o Juiz na tomada de decisão.

\subsubsection{Entrega do Laudo e o levantamento dos honorários}

Na Justiça Trabalhista e Cível, um Contador, ao atuar como perito, tem inteira autonomia para elaborar o Laudo Pericial, e, ao submeter ao juízo competente, basta tão somente sua assinatura para atestar a legitimidade da peça.

Neste sentido, explica Santos (2003, p. 21): "o laudo deverá ser apresentado e protoco- lado mediante petição. $\mathrm{O}$ requerimento do alvará para levantamento dos honorários periciais poderá estar contido na petição de apresentação do laudo ou em petição apartada."

Como visto na atuação pericial, o Contador, ao desenvolver seu trabalho, assina a peça e apresenta ao juízo; no entanto, na Justiça Eleitoral, dependerá da assinatura de um advogado para apresentar a prestação de contas feita por ele. Em analogia ao que acontece na Justiça Comum, também deveria acontecer na Justiça Eleitoral, uma vez que a prestação de contas é um trabalho de atribuição tão somente do Contador, portanto deve ser dispensável a rubrica de um advogado.

\section{QUANTO À ÉTICA DO ADVOGADO}

A ética profissional é um conjunto de normas e valores de comportamento e de relacionamento adotados no âmbito profissional, no exercício de qualquer atividade. Ter uma conduta ética é saber construir relações de qualidade com a profissão, contribuir para o bom funcionamento das atividades de trabalho e para a formação de uma imagem positiva da profissão perante os públicos de interesse, tais como os clientes e a sociedade em geral.

Líderes de empresas e organizações têm defendido que bons ambientes profissionais de trabalho, com relacionamentos amigáveis e respeitosos, contribuem para o aumento do nível de confiança e comprometimento entre os profissionais das mais distintas áreas de atuação, refletindo no bom desempenho de trabalho e no desenvolvimento das diversas profissões. E que comportamentos antiéticos prejudicam as estruturas organizacionais, assim como o melhor desempenho de outras categorias profissionais.

$O$ código de ética dos Advogados define conforme: "Art. 34. Constitui infração disciplinar: V - assinar qualquer escrito destinado a processo judicial ou para fim extrajudicial que não tenha feito, ou em que não tenha colaborado." (BRASIL, 1994).

Portanto, a assinatura de um advogado que não tenha participado da elaboração das 
prestações de contas eleitorais constituiu infração disciplinar, na medida em que não é permitido que esse profissional assine a peça para cuja elaboração não tenha contribuído. No que se refere às prestações de contas, esta, sim, é atividade de exclusividade do contador, em razão de exigir conhecimento técnico-cientifico deste profissional. Portanto, mostra-se desnecessária a rubrica de um patrono nas peças eleitorais confeccionadas por um Contador.

\section{RESULTADOS E CONSIDERAÇÕES FINAIS}

A partir da análise comparativa da legislação e dos autores (bibliografias) que tratam do tema objeto deste ensaio, verificou-se que a confecção de todas as peças que compõem a prestação de contas dos partidos políticos, dos candidatos e dos comitês financeiros é atividade exclusiva dos profissionais de contabilidade.

Em conformidade com a análise feita desde a publicação da Lei 9.096, de 19 de setembro de 1995, e da Lei Eleitoral 9.504, de 30 de setembro de 1997, torna-se obrigatório aos Partidos Políticos, aos Candidatos e aos comitês Financeiros proceder às Prestações de Contas. Sabe-se que os Partidos Políticos Prestam Contas Anualmente, já os candidatos prestam contas sempre ao final de cada eleição.

Contudo, apesar dessa obrigatoriedade aos Partidos Políticos, aos Candidatos e aos comitês Financeiros de procederem às Prestações de Contas, ao longo dos anos, vinham atuando sem a obrigação de fazê-las, sem que essa tarefa fosse executada por um profissional da contabilidade e sem que os órgãos de fiscalização da classe contábil tomassem uma atitude mais enérgica no sentido de tornar obrigatório, por exemplo, patrocinar ação no STF no sentido de exigir que a atividade seja exclusiva de profissional da contabilidade.

A obrigatoriedade para que os Partidos Políticos, os Candidatos procedam às Prestações de Contas por um profissional de contabilidade veio a partir das eleições de 2014, porém, acompanhada da obrigatoriedade de elas também virem assinadas por um Advogado. Com isso, o Tribunal Superior Eleitoral abriu uma janela nas peças da prestação de contas elaboradas pelos profissionais da contabilidade no sentido de que elas pudessem ser assinadas por eles.

Portanto, o problema da pesquisa em comento está relacionado em buscar a dignidade dos profissionais da contabilidade, assim como a dignidade e a ética do advogado. O simples fato de os processos de prestação de contas terem adquirido natureza Jurídica, os trabalhos executados pelos contadores é de sua competência e exclusividade; a janela que se abriu nas peças contábeis de prestação de contas para que o advogado pudesse assinar o trabalho realizado pelo contador não elimina sua natureza administrativa.

Além disso, na realização do trabalho, revisou-se a legislação e a bibliografia pertinente acerca dos encaminhamentos dos laudos periciais elaborados por doutrinadores e sua apresentação de forma que é assegurado por lei e Normas Brasileiras de Contabilidade que é o Perito Contador que peticiona ao juízo, apresentando o trabalho por ele elaborado, no caso em comento, o Laudo Pericial. Já em relação à prestação de contas dos Partidos Políticos, a dos Candidatos, para que o contador leve o resultado de seu trabalho a juízo, é necessário que conste nele a assinatura de um Advogado.

Conclui-se que, se na Justiça Trabalhista, na Justiça Federal, na Justiça Estadual, o Contador atua como Perito Contador encaminhando os Laudos Periciais, ou respostas formuladas pelo Juiz, quando necessário for, para tirar dúvidas que ainda restarem do magistrado. Sendo assim, o contador pode encaminhar as peças das prestações de contas à Justiça Eleitoral, além de responder às diligências questionadas pelo juízo.

Para tal, entende-se que se torna suficiente que a Prestação de Contas dos Partidos Políticos e dos Candidatos se torne atividade exclusiva dos Contadores e sua apresentação por analogia ao que dispõe o artigo 477 CPC quanto aos encaminhamentos dos laudos peri- 
ciais feito pelos Peritos Contadores. Com isso, elimina-se a redundância de que o contador, para poder apresentar o resultado de seu trabalho em juízo eleitoral, tenha que, obrigatoriamente, está munido da assinatura do Advogado que não o fez.

\section{THE ROLE OF THE ACCOUNTANT IN THE PROVISION OF ELECTORAL ACCOUNTS}

\begin{abstract}
The objective of this essay is to analyze the role of the accountant in the provision of the electoral accounts, both for the candidates as for the political parties, evidencing the activities of the accountants, as he does most of the work in relation to the accounting requirements, from the accounting classifications, the typing of the financial operations of the campaign funding and spending, to the preparation and presentation of the accounting reports. However, to present this result to the judge, the signature of a lawyer is necessary, no matter if he has participated or not in the development of the electoral accounts. In other judgments, such as of the Labour and Civil Courts, the accountant is considered an expert and presents the Expert Reports directly to the office, therefore it isn't necessary that a lawyer signs the accounting statements. Given this, the main results allow to conclude that the financial expertise is exclusively of the accountant and, in this way, he should be able to present his work, as well as to respond to the proceedings as they may be demanded, without the interfering of a lawyer signing for something he didn't prepare. Considering, also, that the proprietor did not participate in the elaboration of the electoral accounts nor in the electoral acountability, this situation violates the Lawyer's Code of Ethics.
\end{abstract}

Keywords: Accountant. Lawyer. Electoral Accountability.

\section{EL PAPEL DEL CONTADOR EN LA PRESTACIÓN DE LAS CUENTAS ELECTORALES}

\section{RESUMEN}

Este ensayo tiene por objetivo analizar el papel del contador en la "Prestación de Cuentas de los Partidos Políticos y de los Candidatos", evidenciando las actividades de los contadores, teniendo en cuenta que este profesional desarrolla el trabajo, desde las clasificaciones contables hasta las digitaciones de los movimientos financieros de las recaudaciones y de los gastados de campaña, así, al final de la elaboración del trabajo desarrollado, son presentadas como resultado las piezas contables. Con todo, para que se pueda presentar ese resultado al juez, es necesaria la firma de un abogado, aunque no tenga participado en el desarrollo del servicio contable. En otros juicios, como en la justicia del trabajo y jurisdicciones civiles, el contador, actuando en cuanto perito, presenta los laudos periciales directamente en registro, en lo que es, por tanto, desnecesaria la figura del abogado en las piezas contables. Ante a eso, los principales resultados de esa investigación permiten concluir que la pericia es de exclusividad del contador y, en ese aspecto, él debe presentar su trabajo, así como contestar a las diligencias que le sean requeridas, sin que un abogado firme lo que no fue por él realizado, teniendo en cuenta que él no participó en la elaboración contable, y que dicha situación hiere el Código de Ética de los Abogados.

Palabras clave: Contador. Abogado. Prestación de Cuentas Electorales.

\section{REFERÊNCIAS}

BRASIL. Lei $n^{\circ} 8.906$, de 4 de julho de 1994. Dispõe sobre o Estatuto da Advocacia e a Ordem dos Advogados do Brasil (OAB). Presidência da República do Brasil, Brasília, DF, 1994. Disponível em: <http://www.planalto. gov.br/ccivil_03/leis/L8906.htm>. Acesso em: 
30 jun. 2016.

Lei ${ }^{\circ}$ 9.096, de 19 de setembro de 1995. Dispõe sobre partidos políticos, regulamenta os arts. 17 e 14, $\S 3^{\circ}$, inciso V, da Constituição Federal. Presidência da República do Brasil, Brasília, DF, 1995. Disponível em: $<$ http://www.planalto.gov.br/ccivil_03/leis/ L9096.htm>. Acesso em: 30 jun. 2016.

Lei $\mathrm{n}^{0}$ 9.504, de 30 de setembro de 1997. Estabelece normas para as eleições. Presidência da República do Brasil, Brasília, DF, 1997. Disponível em: <http://www.planalto. gov.br/ccivil_03/LEIS/L9504.htm>. Acesso em: 30 jun. 2016 .

Tribunal Superior Eleitoral. Resolução $\mathrm{n}^{\mathrm{o}} 21.841$, de 22 de junho de 2004. Disciplina a prestação de contas dos partidos políticos e a Tomada de Contas Especial. Processo Administrativo $\mathrm{n}^{\mathrm{o}} 16.443$ - Classe $19^{\mathrm{a}}$ - Distrito Federal - Brasília. Relator: Ministro Fernando Neves. Tribunal Superior Eleitoral, Brasília, DF, 2004. Disponível em: <http://www.tse. jus.br/legislacao-tse/res/2004/RES218412004. htm>. Acesso em: 30 jun. 2016.

. Tribunal Superior Eleitoral. Resolução $\mathrm{n}^{\mathrm{o}} 23.463$, de 15 de dezembro de 2015. Dispõe sobre a arrecadação e os gastos de recursos por partidos políticos e candidatos e sobre a prestação de contas nas eleições de 2016. Tribunal Superior Eleitoral, Brasília, DF, 2015a. Disponível em: $<$ http://www.tse.jus.br/legislacao-tse/res/2015/RES234632015.html>. Acesso em: 30 jun. 2016.

Lei no ${ }^{\circ} 13.105$, de 16 de março de 2015. Código de Processo Civil. Presidência da República do Brasil, Brasília, DF, 2015b. Disponível em: http://www.planalto.gov.br /ccivil_03/_ato2015-2018/2015/lei/113105. htm>. Acesso em: 30 jun. 2016.

CABRAL, Alberto Franqueira. Manual da prova pericial. Rio de Janeiro: Impetus, 2003.
GIAVARINA, Valmor. Eleições 2002. Brasília: [s.n.], 2002.

Eleições 2004. Brasília: [s.n.], 2004.

GIL, Antônio Carlos. Métodos e técnicas de pesquisa social. 6. ed. São Paulo: Atlas, 2008.

KRAEMER, Maria Elisabeth Pereira. Mudanças no perfil do profissional contábil no Mercosul. Revista Brasileira de Contabilidade, Brasília, v. 29, n. 123, p. 52-55, maio/jun. 2000.

MATTOS, José João Appel. Partidas dobradas, contabilidade necessária. Brasília: Econet, 2014.

PORTAL DE CONTABILIDADE. Normas Brasileiras de Contabilidade T13.6. Brasília: Conselho Federal de Contabilidade, 2005. Disponível em: <http://www.portaldecontabilidade.com.br/nbc/t13.htm>. Acesso em: 30 jun. 2016.

SANTOS, Nelson dos. Manual de perícia contábil judicial. Goiânia: Max Gráfica e Editora Ltda, 2003.

SILVA, Antônio Carlos Ribeiro. Metodologia da pesquisa aplicada à Contabilidade: orientações de estudos, projetos, relatórios, monografias, dissertações, teses. São Paulo: Atlas, 2003. 